\title{
Infliximab Treatment Prevents Hyperglycemia and the Intensification of Hepatic Gluconeogenesis in an Animal Model of High Fat Diet-Induced Liver Glucose Overproduction
}

\author{
Karissa Satomi Haida ${ }^{1}$, Gabriela Bertachini ${ }^{1}$, Thauany Tavoni $^{1}$, Márcio Guilhermetti ${ }^{1}$, \\ Marco Rocha Loures ${ }^{2}$ and Roberto Barbosa Bazotte ${ }^{1 *}$ \\ ${ }^{I}$ Departamento de Farmacologia e Terapêutica Clínica; Universidade Estadual de Maringá. ${ }^{2}$ Departamento de \\ Medicina; Universidade Estadual de Maringá; Av. Colombo, 5790; 87020-900; Maringá - PR - Brasil
}

\begin{abstract}
The effect of infliximab on gluconeogenesis in an animal model of diet-induced liver glucose overproduction was investigated. The mice were treated with standard diet (SD group) or high fat diet (HFD group). HFD group were randomly divided and treated either with saline (100 $\mu \mathrm{l} /$ dose, ip, twice a day) or infliximab (10 $\mu \mathrm{g}$ in $100 \mu \mathrm{l}$ saline per dose, ip, twice a day, i.e., $0.5 \mathrm{mg} / \mathrm{kg}$ per day). SD group also received saline. The treatment with infliximab or saline started on the first day of the introduction of the HFD and was maintained during two weeks. After this period, the mice were fasted $(15 \mathrm{~h})$ and anesthetized. After laparotomy, blood was collected for glucose determination followed by liver perfusion in which L-alanine (5 mM) was used as gluconeogenic substrate. HFD group treated with saline showed higher $(p<0.05)$ liver glucose production from L-alanine and fasting hyperglycemia. However, these metabolic changes were prevented by infliximab treatment. Therefore, this study suggested that infliximab could prevent the glucose overproduction and hyperglycemia related with glucose intolerance and type 2 diabetes.
\end{abstract}

Key words: Infliximab, hyperglycemia, TNF-alpha, liver gluconeogenesis, type 2 diabetes, mouse

\section{INTRODUCTION}

Liver glucose overproduction, particularly gluconeogenesis is a key element of hyperglycemia in prediabetes and type 2 diabetes (Monnier et al. 2008). For this reason, metformin has become a mainstay in the modest therapeutic armamentarium to prevent the liver glucose overproduction (Viollet et al. 2009) and represents the first line oral treatment for patients who are unable to achieve glycemic control with diet and exercise (ADA 2010). However, metformin shows several adverse effects, including nausea, vomiting, diarrhea, flatulence (Florez et al. 2010) and is contraindicated in conditions that could increase the risk of lactic acidosis, including kidney disorders, lung disease and liver disease (Friesecke et al. 2010).

Considering that except metformin there are only a few pharmacological alternatives to reduce the liver glucose overproduction (ADA 2010; Tomas et al. 2010), the development of new drugs, which influences this metabolic process must be investigated. In this context, the anti-TNF-alpha

*Author for correspondence: rbbazotte@uem.br 
monoclonal antibody infliximab showed beneficial effects not only for the diseases such as rheumatoid arthritis, Crohn's disease, and psoriatic arthritis (Karampetsou et al. 2010) but also for type 2 diabetic patients (Ursini 2009; Ursini et al. 2010; Yazdani-Biuki et al. 2006). The mechanism by which infliximab improves the glycemic control involves an inactivation of TNF-alpha activity (Yazdani-Biuki et al. 2006; Ursini 2009). Moreover, a previous study showed that the treatment with infliximab improved the signal transduction through the insulin receptors in liver in an animal model of diet-induced obesity and diabetes (Araújo et al. 2007). However, the effect of infliximab on liver glucose overproduction was not investigated.

Therefore, in this study an animal model of dietinduced liver glucose overproduction was used to determine the effect of infliximab on liver gluconeogenesis from L-alanine. The reason of using this amino acid was based on the following facts that L-alanine was the main gluconeogenic substrate and its conversion to glucose used all the steps of the gluconeogenic pathway (OliveiraYamashita et al. 2009).

\section{MATERIALS AND METHODS}

L-alanine was obtained from ICN Biochemichals (Costa Mesa, CA, USA). Infliximab was purchased from Centocor (Horsham, PA, USA). All other reagents were of the highest purity obtainable.

The mice (30-35 g) were maintained with constant temperature $\left(23^{\circ} \mathrm{C}\right)$ and automatically controlled photoperiod (12-h light/12-h dark).

The high fat diet was obtained by the addition of pork fat (Sadia $\left.{ }^{\circledR}\right)$ in the regular rodent chow (Nuvital ${ }^{\circledR}$ ) increasing the lipid composition from 4.5 to $48 \%$. The control group received regular rodent chow (Nuvital@).

Mice were treated either with a standard diet (SD group) or with a high fat diet (HFD group) during two or four weeks. Since fasting hyperglycemia was well established two weeks after the introduction of the HFD diet (not shown), this period of treatment was used in the next set of experiments. For this purpose, HFD group were randomly divided and treated either with saline (100 $\mu \mathrm{l} /$ dose, ip, twice a day) or with infliximab (10 $\mu \mathrm{g}$ in $100 \mu \mathrm{l}$ saline per dose, ip, twice a day). Moreover, SD group also received saline (100 $\mu 1 /$ dose, ip, twice a day).

The daily dose of infliximab $(0.5 \mathrm{mg} / \mathrm{kg})$ and schedule of administration (9:00 a.m. and 5:00 p.m.) were based on a previous study (Araújo et al. 2007). The treatment with infliximab or saline started on the first day of the introduction of the HFD and was maintained until the day before the experiments when the animals were food deprived from 5:00 p.m. All the experiments were performed in $15 \mathrm{~h}$ fasted mice (5:00 p.m. - 8:00 a.m.) when the mice were anesthetized with ip thiopental $(120 \mathrm{mg} / \mathrm{kg})$. After laparotomy, blood was collected from the cava vein for glucose determination (Bergmeyer and Bernt 1974) and the liver perfusion was started immediately.

The in situ liver perfusion technique was done as previously described (Galende et al. 2009; Oliveira-Yamashita et al. 2009). Figure 1 showed a demonstrative experiment in which after a preinfusion period $(10 \mathrm{~min})$, L-alanine was infused during $60 \mathrm{~min}$, followed by a post-infusion period (10 min without L-alanine) to allow the return of basal glucose production values of the pre-infusion period. The samples of the effluent perfusion fluid were collected each $5 \mathrm{~min}$ and the glucose concentration was measured. The difference between the glucose production during and before L-alanine infusion represented the glucose production from gluconeogenesis. The areas under the curves (AUC) of the infusion period with Lalanine were expressed as $\mu \mathrm{mol} / \mathrm{g}$. In addition to glucose (Bergmeyer and Bernt 1974), the production of pyruvate (Czok and Lamprecht 1974), urea (Gutmann and Bergmeyer 1974) and L-lactate (Gutmann and Wahlefeld 1974) in the liver were also evaluated. At the end of the experiment, the liver was removed and weighed to allow precise metabolic calculations and the correction of flow rates.

The program GraphPad Prism (version 6.0) was used to calculate the AUC. Data were analyzed statistically by the unpaired Student's $t$-test. A 95\% level of confidence $(\mathrm{p}<0.05)$ was accepted for all the comparisons. Results are reported as means \pm standard deviation (SD). 


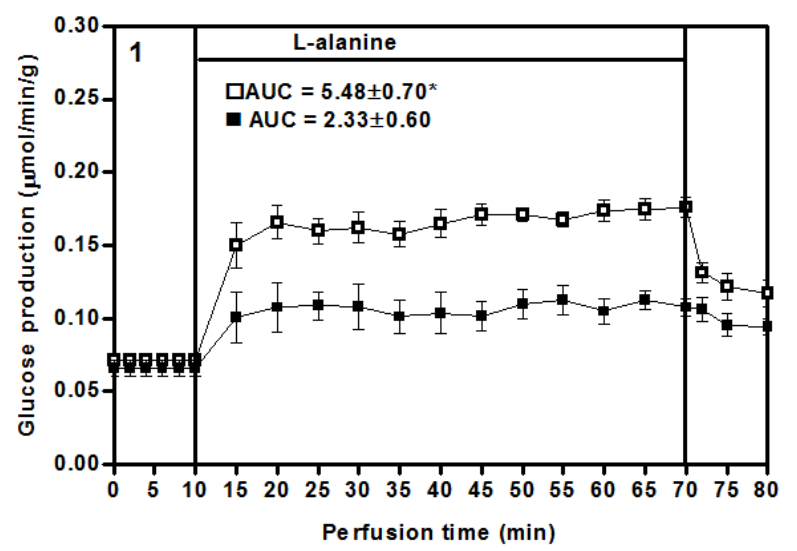

Figure 1 - Demonstrative experiments of glucose production from L-alanine $(5 \mathrm{mM})$ in perfused livers from mice treated with standard diet (ם) or high fat lipid diet ( $\square$ ) during two weeks. The efluent perfusate was sampled in 5 min intervals and analyzed for glucose. The livers were perfused as described in materials and methods. The data are reported as the mean \pm SD of $3-5$ individual experiments. $* \mathrm{p}<0.05$.

\section{RESULTS}

The treatment with infliximab during two weeks did not change caloric intake and body weight (Results not shown).

Since in situ perfused livers reflected the in vivo conditions of the animal immediately before the liver isolation (Galende et al. 2009; OliveiraYamashita et al., 2009) and considering that mice treated with a HFD were a suitable experimental model to induce the liver glucose overproduction (Tomas et al. 2010; Wu et al. 2010), this experimental approach was used.

As showed by Table 1, the treatment with infliximab prevented the glucose overproduction during the infusion of L-alanine in the liver from HFD mice ( $<<0.05$ : HFD + Infliximab vs. HFD + Saline). This result could be attributed, partly at least, to the decreased catabolism of L-alanine, since the L-lactate production from this amino acid was also decreased ( $\mathrm{p}<0.05$ : HFD + Infliximab vs. HFD + Saline) and urea production showed a clear tendency to decrease ( $p>0.05$ : HFD + Infliximab vs. HFD + Saline). Moreover, since pyruvate production from L-alanine showed clear tendency to be higher ( $\mathrm{p}>0.05$ : HFD + Infliximab vs. HFD + Saline), the possibility of a lower entrance of pyruvate in the gluconeogenic pathway must be considered.

Table 1 - Area under curves (AUC) of glucose, L-lactate, urea and pyruvate production ( $\mu \mathrm{mol} / \mathrm{g})$ from L-alanine (5 $\mathrm{mM}$ ) in perfused livers from fasted mice treated with standard diet (Control) or high fat diet (HFD) + saline or HFD + Infliximab. The livers were perfused as described in Materials and Methods. The data (AUC) are reported as $\underline{\text { means } \pm \text { SD (3-5 mice per group). } * p<0.05 v s . ~ H F D+\text { Saline. }}$

\begin{tabular}{cccc}
\hline & CONTROL & HFD + Saline & HFD + Infliximab \\
\hline Glucose & $2.67 \pm 1.46^{*}$ & $6.58 \pm 2.03$ & $2.34 \pm 1.16^{*}$ \\
L-Lactate & $0.87 \pm 0.43^{*}$ & $6.88 \pm 1.74$ & $3.35 \pm 2.00^{*}$ \\
Urea & $2.50 \pm 1.46^{*}$ & $7.20 \pm 2.99$ & $4.94 \pm 2.17$ \\
Pyruvate & $0.91 \pm 0.33^{*}$ & $2.01 \pm 0.73$ & $2.75 \pm 0.58$ \\
\hline
\end{tabular}

\section{DISCUSSION}

This is the first evidence showing that infliximab could prevent the liver glucose overproduction. The mechanism involved in this effect remained to be investigated. However, the inactivation of TNFalpha might play a key role in this process (Ursini et al., 2010; Yazdani-Biuki et al. 2006). In fact, it is well established that TNF-alpha from adipocytes disrupts the insulin signaling machinery by 
activating serine kinases that targets the proteins such as the insulin receptor (IR)/ IR substrate1(IRS-1), and IR substrate-2 (IRS-2), producing insulin resistance (Lorenzo et al. 2008). Moreover, the mechanism by which infliximab promotes the inhibition of gluconeogenesis and reduction of fasting glycemia certainly involves improvement in insulin signal transduction through IR/ IRS-1 and IRS-2/ Akt/ forkhead box protein O1 (FOXO1) pathway (Araújo et al. 2007). The values of glycemia for SD group, HFD group treated with saline and HFD group treated with infliximab were $66.1 \pm 15.5,93.4 \pm 25.9$ and 66.8 \pm 15.5 , respectively. Therefore, consistent with the results of liver glucose production from Lalanine, HFD + infliximab group showed lower glycemia if compared with HFD mice treated with saline ( $<$ <0.05: HFD + Infliximab vs. HFD + Saline). It should be noticed that a direct effect of infliximab treatment lowering glycemia was previously demonstrated (Araújo et al. 2007).

Thus, it could be concluded that this investigation provided additional support for the role of TNFalpha in the pathogenesis of diabetes and suggested that the pharmacological inhibition of TNF-alpha by infliximab could be an attractive approach for the prevention of glucose overproduction related with glucose intolerance and type 2 diabetes. On the other hand, considering that metformin decreases glucose overproduction by a different mechanism and participates in regulating the release of TNF alpha (Labuzek et al. 2010), the possibility of the combination of these drugs must be considered.

\section{ACKNOWLEDGEMENTS}

The authors are grateful to Mr. Carlos Eduardo de Oliveira and Solidalva Caruso de Oliveira for their technical assistance during the experiments. Research supported by CNPq (Grant number 563870/2010-9), CAPES and Fundação Araucária.

\section{REFERENCES}

American Diabetes Association - ADA. Standards of Medical Care in Diabetes. Diabetes Care 2010; 33: S11-S61.
Araújo EP, De Souza CT, Ueno M, Cintra DE, Bertolo $\mathrm{MB}$, Carvalheira JB et al. Infliximab restores glucose homeostasis in an animal model of diet-induced obesity and diabetes. Endocrinology 2007; 148: 5991-5997.

Bergmeyer HU, Bernt E. Determination of glucose with glucose oxidase and peroxidase. In: H. U. Bergmeyer (Ed.), Methods of enzymatic analysis, New York: Verlag Chemie-Academic Press; 1974, pp. 12051215.

Czok R, Lamprecht W. Pyruvate, phosphoenolpyruvate and D-glycerate-2-phosphate. In: H. U. Bergmeyer (Ed.), Methods of enzymatic analysis, New York: Verlag Chemie-Academic Press; 1974, pp. 14461448.

Florez H, Luo J, Castillo-Florez S, Mitsi G, Hanna J, Tamariz L et al. Impact of metformin-induced gastrointestinal symptoms on quality of life and adherence in patients with type 2 diabetes. Postgrad Med. 2010; 122: 112-120.

Friesecke S, Abel P, Roser M, Felix SB, Runge S. Outcome of severe lactic acidosis associated with metformin accumulation. Crit Care 2010; 14: R226.

Galende SB, Oliveira-Neto OC, Santos LF, Peicher MV, Souza HM, Bazotte RB. Glucose administration inhibits the hepatic activation of gluconeogenesis promoted by insulin-induced hypoglycemia. Braz Arch Biol Technol. 2009; 52: 849-854.

Gutmann I, Bergmeyer HU. Determination of urea, indicator reaction with phenol and hypochlorite. In: H. U. Bergmeyer (Ed.), Methods of enzymatic analysis, New York: Verlag Chemie-Academic Press; 1974, pp. 1790-1798.

Gutmann I, Wahlefeld W. L-(+)-Lactate. Determination with lactate dehydrogenase and NAD. In: H. U. Bergmeyer (Ed.), Methods of enzymatic analysis, New York: Verlag Chemie-Academic Press, 1974; pp. 1464-1472.

Karampetsou MP, Liossis SN, Sfikakis PP. TNF- $\alpha$ antagonists beyond approved indications: stories of success and prospects for the future. QJM 2010; 103: 917-28.

Łabuzek K, Liber S, Gabryel B, Okopień B. Metformin has adenosine-monophosphate activated protein kinase (AMPK)-independent effects on LPSstimulated rat primary microglial cultures. Pharmacol Rep. 2010; 62: 956-965.

Lorenzo M, Fernández-Veledo S, Vila-Bedmar R, Garcia-Guerra L, De Alvaro C, Nieto-Vazquez I. Insulin resistance induced by tumor necrosis factoralpha in myocytes and brown adipocytes. J Anim Sci. 2008; 86: 94-104.

Monnier L, Colette C, Owens DR. Type 2 diabetes: a well-characterised but suboptimally controlled disease. Can we bridge the divide?; Diabetes Metab. 2008; 34: 207-216. 
Oliveira-Yamashita F, Garcia RF, Felisberto-Junior AM, Curi R, Bazotte RB. Evidence that L-glutamine is better than L-alanine as gluconeogenic substrate in perfused liver of weaned fasted rats submitted to short-term insulin-induced hypoglycaemia. Cell Biochem Funct. 2009; 27: 30-34.

Tomas E, Stanojevic V, Habener JF. GLP-1 (9-36) amide metabolite suppression of glucose production in isolated mouse hepatocytes. Horm Metab Res. 2010; 42: 657-662.

Ursini F, Succurro E, Grembiale A, Rudi S, Grembiale RD, Arturi F. Sudden progression from impaired glucose tolerance to type 2 diabetes after discontinuation of administration of anti-tumor necrosis factor-alpha antibody infliximab. Int $J$ Immunopathol Pharmacol. 2010; 23: 961-633.

Ursini F. TNF-alpha and insulin-resistance: metabolic effects of in vivo therapeutic blockade. Reumatismo 2009; 61: 254-259.
Viollet B, Guigas B, Leclerc J, Hébrard S, Lantier L, Mounier R et al. AMP-activated protein kinase in the regulation of hepatic energy metabolism: from physiology to therapeutic perspectives. Acta Physiol. (Oxf) 2009; 196: 81-98.

Wu Z, Jiao P, Huang, X, Feng B, Feng Y, Yang S et al. MAPK phosphatase-3 promotes hepatic gluconeogenesis through dephosphorylation of forkhead box O1 in mice. J Clin Invest. 2010; 120: 3901-3911.

Yazdani-Biuki B, Mueller T, Brezinschek HP, Hermann J, Graninger W, Wascher TC. Relapse of diabetes after interruption of chronic administration of antitumor necrosis factor-alpha antibody infliximab: a case observation. Diabetes Care 2006; 29: 17121713.

Received: February 26, 2011; Revised: June 21, 2011; Accepted: March 09, 2012. 


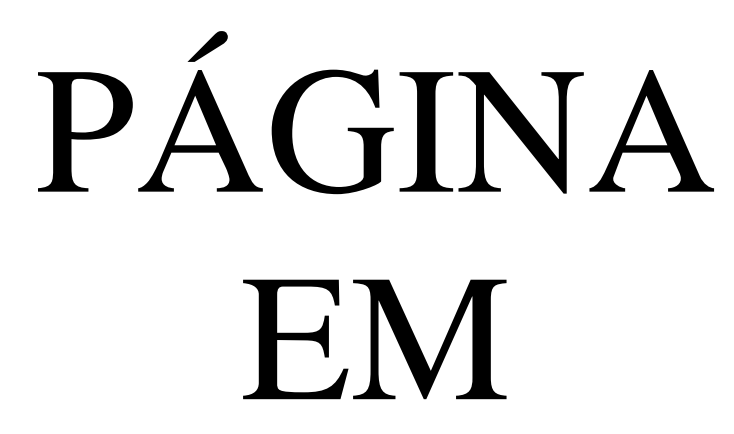

BRANCO 